\title{
Network Organization of Citizen Agent Service: A New Way to Improve the Chinese Citizen Agency System in the Era of Big Data
}

\begin{abstract}
Rui $\mathrm{Xu}^{*}$
Shanghai University of Political and Law, Shanghai, China

*Corresponding author.Email: xr0903@163.com

ABSTRACT

For a long time, there is a huge demand for civil litigation agency in China. However, under the circumstance that professional lawyers are obviously insufficient in civil litigation, it is difficult to examine the qualifications of non-professional lawyers as civil agents, as well as the supervision of their work, which has been restricting the implementation of the civil agency system. The era of big data promotes the rise of network organizations, which brings a solution to the dilemma of citizen agency review and supervision. Through the construction of citizen agent service network organization by the the way of "double subject" collaborative innovation of government and Universities, humanized law design, "all fields" Data driven, certificated volunteer service and Intelligent" network operation, there is hope to effectively solve the Institutional Dilemma and further improve the citizen agency system.
\end{abstract}

Keywords: Citizen agency, Big data, Volunteer service, Network organization.

\section{公民代理服务网络组织: 大数据时代完善中国公民代理 制度的新途径}

徐锐*

\author{
上海政法学院，上海，中国 \\ *通讯作者. 邮箱: xr0903@163.com
}

\section{中文摘要}

长久以来, 公民诉讼代理在中国存在巨大的需求。但是, 在职业法律人参与民事诉公中公民代理明显不足的情 况下, 非职业法律人担任公民代理人的资质审查难及公民代理行为监管难问题一直制约着公民代理制度的施行。 大数据时代推动了网络组织的兴起, 为消解公民代理审查监管难的困境带来解决方案。通过政府与高校的“双 主体”协同创新、“人性化”法规设计、“全领域”数据驱动、“认证式”志愿服务和“智能化”网络运营五个方面构建 设计公民代理服务网络组织, 可望有效解决制度性困境, 进一步完善公民代理制度。

关键词：公民代理，大数据，志愿服务，网络组织

从司法实践看，中国施行公民代理制度是为了满 足因没有律师强制代理制度而产生的法律援助制度 供给不足的需要。然而, 长久以来, 公民代理所要求
的法律专业性和法律援助普适性之间存在矛盾。在职 业法律人参与公民代理明显不足的情况下, 非法律职 业公民担任代理人的资质审查难、公民代理行为监管 
难及其衍生出的一系列问题一直困扰着公民代理制 度的实施, 甚至引发学界争论是否应该取消公民代理 制度。2012 年，全国人大修订了民事诉讼法，2015 年, 最高人民法院颁布了适用民事诉讼法的解释。相 关法规不仅未取消公民代理制度，而是对有关公民代 理的资格条件进行了进一步的修改和明确, 这既表明 了国家对于发展公民代理制度的期待, 也为社会组织 团体参与公民代理活动提供了法律依据。与此同时, 大数据正日益与政府治理融合为数据化的政府治理。 大数据时代的政府治理应从传统的依靠人为主观经 验和直觉判断进行决策转为数据驱动的决策, 变政府 “一元”治理为“政府一一社会”多元治理, 从而使政府 能够更多地基于事实做出判断, 解决体制内难以独立 完成的问题。通过发挥政府与社会组织协同创新的优 势, 研究设计多部门通用共享的大数据开放、获取和 应用机制, 构建基于大数据驱动的公民代理服务网络 组织, 可望成为消解公民代理人资质审查和行为监管 困境, 从而更好地推动公民代理制度实施的新途径。

\section{1. 审查监管难：中国公民代理制度存在的困} 境

中国的法律援助制度自建立以来, 一直面临着经 费短缺、法律援助人力资源不足与巨大的法律援助需 求之间的矛盾。而公民代理作为法律援助制度的补充, 被规定不得以牟利为目的。在律师队伍的人数尚不能 满足日益增长的诉讼服务需求的情况下, 由于律师参 与公民代理的意愿不足, 而基层法律服务工作者又被 现行民事诉讼法限定不得以公民身份进行民事诉讼 代理, 因此, 公民代理实际上是指当事人委托非法律 职业人士的普通公民代理诉讼的行为。2012 年修订 民事诉讼法以前的旧民事诉讼法显示出了鼓励非法 律职业公民从事公民代理的导向。根据旧民事诉讼法 第 58 条规定, 可以担任公民代理人的条件很宽泛, 只要法院许可, 普通公民即可担任公民代理人。但法 院限于时间成本和人力资源成本, 只能对代理人的资 格进行形式审查, 甚至往往对公民代理申请人与代理 人达成合意的案件直接予以立案, 这就产生了诸多问 题。例如, 一些非法律职业从业者的公民代理人由于 缺乏系统法学教育和诉讼实践经验, 影响了案件的诉 讼质量, 甚至把原本可能胜诉的案件打成败诉, 损害 了当事人的合法权益; 一些公民代理人违法收费, 甚 至形成了以牟利为生的职业公民代理人, 扰乱了法律 服务市场的正常秩序，等等。

为此, 2012 年《民事诉讼法 (修正案)》对第 58 条有关公民代理制度的条款进行了修改。新法第 58 条删除了原法条中“经人民法院许可的其他公民”这 一表述, 明确了能够被委托作为诉讼代理人的除了有 “律师、基层法律服务工作者”这一类职业法律人之外， 只有“当事人的近亲属或者工作人员; 当事人所在社 区、单位以及有关社会团体推荐的公民”这两类非法 律职业公民。而 2015 年最高人民法院《关于适用《中 华人民共和国民事诉讼法》的解释》（法释（2015）5
号) 第 85 条至 87 条又针对如何认定当事人的近亲属 或者工作人员, 以及有关社会团体如何推荐公民担任 诉讼代理人的条件和范围作了更为详细的规定。可以 看出, 新法条的重点是试图进一步严格地限制担任公 民代理人的非职业法律公民的身份范围, 来规范公民 代理制度的实施。但是, 这种“以身份划范围”式的限 制并没有起到解决非法律职业公民担任代理人的审 查难的效果。由于对公民代理人资格审查程序、相关 方面责任认定、操作细则、惩处措施等缺乏相关配套 制度和规定，导致在司法实践中，相关责任方既缺乏 对非职业法律公民担任公民代理人的资格审查的意 识和专业能力, 也缺乏承担资格审查责任的动力, 致 使新法条虽然在形式上免除了法院的审查责任, 而在 实践中法院依然不得不承担资质审查“最后把关人” 的责任。但法院限于人员精力和审查成本, 依然只能 对公民代理人的资格进行形式审核。因此，公民代理 人资格审查难始终难以解决, 而对代理人资格的严格 限制反而导致许多真正需要进行公民代理的当事人 无法得到救助, 进而引发对司法机关的误解、不满和 抵触情绪；还产生了诸如“冒用律师或基层法律服务 工作者身份从事诉讼代理活动”、隐形职业公民代理”、 虚构代理人劳动关系、通过疏通与当事人社区审查人 的关系获取代理资格等新的违法代理行为。

由于在传统的政府治理中，对于信息数据的管理 采取“专业部门独立上报模式, 管理相对分散”。因此, 导致公民代理审查监管难及改进对策“失灵”的根本 原因, 在于对公民代理人的审查监管主要依靠政府内 部各有关部门实施“线下单兵作战”式的分散监管, 产 生了审查监管的“盲点”; 没有形成多部门机构的信息 合作和数据共享机制, 产生了信息数据的“孤岛”。虽 然 2012 年修订的民事诉讼法删除了“经法院允许的 其他公民”的表述，试图减轻法院对于公民代理人资 质和行为监管的责任, 并在一定程度上强化了当事人 所在单位、社区和社会团体的监管责任, 但这种基于 身份管理和属地化管理思维的规定无法应对流动性 强或无单位身份的“自由人”的千差万别的情况。这些 当事人的亲属关系和劳动人事关系难以由其所在单 位、社区和社团独立地认定, 且这些单位组织又普遍 缺乏公民代理人资质审查的工作网络和数据库, 相关 信息数据要么以前没有注重积累保存, 要么散落于各 自的工作网络和数据库中, 信息不能共享, 数据也不 能互相导入。因此, 在当事人或代理人提供虚假证明 材料, 而相关单位只能进行形式审查的情况下, 法院、 当事人所在单位、社区和社会团体都无法有效鉴别公 民代理人所提供材料的真实性。

总体看, 当前有关完善公民代理制度的研究和对 策几乎都局限于在政府机构内部“自循环”的视野之 中, 对政府机构与社会组织如何协同开展公民代理服 务, 以及对当事人所在社区、单位特别是社会团体如 何担负起公民代理人资质审查责任的研究几乎空白。 在实践中, 民间法律援助组织也缺乏参与到公民代理 服务中的渠道。总之, 在传统模式下公民代理人资格 
审查难的问题无法得到根本解决, 需要创新理念, 创 新路径。

\section{2. 网络组织理论与公民代理服务网络组织}

21 世纪以来, 互联网和大数据技术的快速发展为 改革创新法律援助制度提供了机遇。不少国家开始利 用大数据技术重构公共法律服务体系，信息化、数字 化被视为应对法律援助经费缩减、密切相关部门之间 协作关系、提供便捷法律援助服务的重要途径。“开 源共享、跨域协同、精准施策”的数据化治理思维有 助于构建形成“政府主导, 社会力量补充”的中国法律 援助模式。与此同时，智力资源、环境适应能力和创 新能力成为 “互联网+”情境下组织赖以生存发展的基 础。跨越政府机构和民间组织的“网络组织”应运而起, 并成为解决公共治理难题的重要组织形式。大数据技 术为降低政府部门与社会组织团体协同合作的成本, 构建形式灵活、数据共享、快速响应、无缝衔接的公 民代理服务的网络组织提供了有利技术条件, 构建公 民代理服务的网络组织有望成为完善公民代理制度 的新途径。

对网络组织的研究起源于企业尝试以跨边界网络 化合作的形式来提升运营效率和利润的努力。

Hopwood（1996）率先提出了对超越企业法定边界互 动问题研究的必要。此后, 网络组织引起学界重视, 并逐步成为组织理论研究的热点。网络组织“是指一 种与科层、市场并不相同的关系形式”。由于网络组 织融合了传统市场组织和科层组织的优点, 后来的研 究者逐渐把对网络组织的研究对象和活动拓展到各 类社会组织。

综上, 可以认为, 网络组织是由若干个独立的组 织为了实现共同的战略目标而组成的半自治联合体, 它融合了传统科层组织与市场运行模式的优点, 基于 成员组织之间的信任和契约关系, 依托互联网信息技 术和大数据技术, 在定义成员角色和任务链职能的基 础上, 通过发挥出自身独特的技术、信息和管理经验 等优势来实现共同追求的目标。组织成员之间基于重 复博弯的集体理性进行长期互动并不断强化相互之 间的合作关系, 使组织成员产生了和谐的价值观归属 感, 增强了网络组织的吸引力与凝聚力, 获得了降本 增效”的“协同效应”, 从而使网络组织获得高于独立 运作绩效的共同治理绩效。

基于网络组织理论构建的公民代理服务网络组织 致力于将分散于政府各部门的公民代理审查监管责 任集中于公民代理服务网络组织中的特定组织成员, 变公民代理由政府部门“内循环”式“分散监管”模式 为“政府部门一社会组织”的“协同监管”模式; 以“大 数据应用 + 认证式志愿服务”的方式消解公民代理审 查监管“盲区”，展现了公民代理制度所具有的法律援 助属性, 并弥补了职业法律人参与公民代理的不足, 从而保障公民代理制度的有效施行。由于职业法律从 业者参与公民代理动机不强, 数量有限, 且社会上符 合法定条件的公民代理人员来源不稳定，流动性较大，
而高校具有同政府机构开展相关合作的诸多优势和 动力, 可以考虑将政府法律援助机构、共青团组织、 高校法学院系和法律援助志愿者组织等政府和社会 组织作为公民代理网络组织的成员。网络组织的所有 组织成员都具有从不同维度开展公民代理援助服务 的共同愿景: 法律援助中心要发挥社会组织力量, 协 同创新公民代理的工作机制; 共青团可以把公民代理 志愿服务扩展成为青少年法律援助志愿服务的新领 域和新形式; 高校希望借助公民代理志愿服务的实践 形式提升法学专业教育质量和社会贡献度; 高校法律 援助志愿者组织则希望通过参与公民代理志愿服务 获得更多的“实战”经验，提升法律援助志愿服务的水 平和能力。这一切为构建公民代理服务网络组织打下 基础。

\section{3. 公民代理服务网络组织的设计构想}

\section{1. “政府+高校”协同创新形成“双核心”主体}

完善公民代理制度需要政府机构和社会组织打通 彼此间的合作壁垒，有效汇聚各类资源，从而“充分 释放彼此间人才、资本、信息、技术等创新要素活力 而实现深度合作”。自 2012 年以来, 教育部启动了“高 等学校创新能力提升计划”, 旨在以人才、学科、科 研三位一体创新能力提升为核心任务, 通过构建面向 科学前沿、文化传承、行业产业以及区域发展重大需 求的四类协同创新模式，深化高校的机制体制改革， 转变高校创新方式, 建立起能冲击世界一流的新优势。 这给予政府机构与高校“强强联合”开展公民代理志 愿服务网络组织的创新实践以有力的政策支撑。高校 具有半官方的社会属性, 具备参与公民代理制度建设 的诸多优势。首先, 高校作为政府机构的延伸, 承担 了政府服务社会的诸多职能。其次，众多高校拥有实 力雄厚的法学专业师资力量, 已经建立了法律援助机 构或志愿服务组织, 具有丰富的法律援助服务实践经 验和成果。其三, 高校开展公民代理志愿服务, 有利 于进一步创新法学专业学生培养模式, 实现提升法学 人才培养的针对性、增进学生就业的竞争力、加强校 企合作和产学研成果转化等多重目标。因此, 将高校 及其所属法律援助志愿者组织打造成为公民代理网 络组织的核心，形成“政府一高校”协同创新的“双主 体”驱动示范效应, 能够鼓励更广泛、更多元化的社 会力量积极参与到公民代理服务事业中来。

\section{2. “人性化”法规设计放宽准入限制}

中国法律援助制度历来倡导“政府法律援助机构 主导，民间公益组织补充”的运作理念。如 《法律援 助条例》第八条明确指出, “国家支持和鼓励社会团 体、事业单位等社会组织利用自身资源为经济困难的 公民提供法律援助”。现行《民事诉讼法》第 58 条指 出, “有关社会团体推荐的公民”能够被委托作为诉讼 代理人。上述条款成为鼓励社会组织和团体开展公民 代理服务的法律依据。最高人民法院关于适用《中华 


\begin{abstract}
人民共和国民事诉讼法》的解释第 87 条规定了社会 团体推荐公民担任诉讼代理人的条件。相关条款应成 为发挥社会法律援助团体和构建高校公民代理志愿 服务社团的建设指南。但第 87 条的第 1 条“社会团体 属于依法登记设立或者依法免予登记设立的非营利 性法人组织”, 以及第 4 条“被推荐的公民是该社会团 体的负责人或者与该社会团体有合法劳动人事关系 的工作人员”的要求过于严格。考虑到高校众多法律 援助性质的社团挂靠在高校, 它们虽然并未在民政部 门登记, 也不属于法人组织, 但由于高校共青团和法 学院系承担着指导、组织和监督社团运行的职责, 因 此在事实上受到了与法定的社会组织团体相同, 甚至 更为严格的约束。高校社团的成员主体是师生, 虽然 而不是“有合法劳动人事关系的工作人员”，但高校对 师生的管理教育涵盖了工作、学习、生活、品行的方 方面面, 特别是高校对学生的影响力和约束力更是超 过了企事业单位对普通员工的影响和约束。有鉴于此, 应对公民代理志愿服务行为设计更为人性化, 更加因 地制宜的评估和制度。可通过进行新的司法解释, 或 在司法实践中进行规制的突破和创新，放宽准入条件， 给予制度保障, 推动其先行先试。例如, 对凡是通过 地方法律援助机构或法院认证或备案的高校公民代 理志愿服务社团, 准许其免予登记或放松登记条件; 被推荐和认证的公民为符合一定的公民代理法律专 业性条件的社团成员, 即可准许其从事公民代理志愿 服务活动等等。
\end{abstract}

\section{3. “全领域”大数据驱动网络组织}

大数据驱动的核心在于信息数据。公民代理服务 网络组织以公民代理服务的信息化、数据化为驱动力, 力图 “用数据说话、用数据决策、用数据管理、用数 据创新”。在实践中, 应通过开放政府相关部门的公 共数据权限、规范公民代理的各类信息数据采集标准、 建立公民代理数据交易机制等多种方式, 实现网络组 织成员之间的数据共享, 缓解和解决公民代理审查监 管的“数据孤岛”问题; 通过在大数据“云端”平台记录 和分析公民代理人的代理行为大数据, 研究设计公民 代理人的行为数据算法, 对每一个代理人进行“数据 画像”, 并在网络组织的成员中共享行为数据, 推动 公民代理人申请备案制、认证免检制和违法黑名单制 的有效施行, 降低公民代理审查监管的操作成本; 通 过在大数据平台的后台进行公民代理数据的深度挖 掘, 开展人群识别、需求识别和案源识别, 关注广大 弱势群体差异性的利益诉求, 提高当事人与代理人的 需求匹配精度, 提升公民代理服务的精准性; 通过设 计云平台和大数据资料库, 提供当事人、代理人与相 关政府工作人员便捷的在线互动机会, 使当事人感受 到政府关爱弱势群体, 提升社会公正度的实在举措, 提高社会法律援助组织参与政府法律援助工作的获 得感。

\section{4. “认证式”志愿服务保障服务质量}

一方面，公民代理制度本身具有天然的法律援助 属性, 相关法律法规还特别规定了公民代理行为的非 营利性, 要求公民代理制度的实施不能扰乱有偿法律 服务的市场行为。这就使公民代理人在实施公民代理 诉讼活动时必须具有贡献自身专业能力, 不求有偿经 济回报, 扶助弱势群体维权, 增进社会公平正义的精 神境界, 这恰恰契合现代社会志愿服务的宗旨和规范。 可以说, 公民代理制度所天然具有的志愿奉献的基因, 使发展公民代理志愿服务成为可能。特别是在律师自 愿履行法律援助义务的供给不足的现状下, 开展志愿 服务成为弥补公民代理服务供给不足的有效途径。另 一方面, 由于公民代理志愿服务具有较强的专业性、 规范性和首创性, 因此需要在大力扶持和引导的基础 上加强监管。参与公民代理服务的志愿者组织虽然各 有差异和特性, 但将其纳入到公民代理服务网络组织 之内, 政府有关部门就可以整合资源, 通过对广大志 愿者进行基于大数据分析的甄别遴选，对符合条件的 志愿者进行认证管理, 使其持证上岗, 从而解决好作 为非职业法律人的志愿者担任公民代理人的资质审 查及公民代理行为监管的关键难题。此外，在公民代 理服务网络组织的内部, 具有管理和指导职能的相关 政府部门可通过行政指令或合作共建的方式进行互 动, 但在面向大众开展公民代理服务的公众层面, 则 可以采取政府组织或购买志愿服务的方式进行运作。

\section{5. “智能化”网络精准执行流程}

依托 $5 G$ 通讯技术和大数据、人工智能技术, 可以 为公民代理服务网络组织设计出能够便捷获取公民 代理供需信息, 智能审查代理人资质材料, 实时提供 公民代理服务, 以及自主有效评估案件质量的“智能 化”服务网络。在线上, 建立公民代理人和案件数据 库, 提供当事人申请公民代理服务的远程网络端口, 对申请公民代理的案件进行在线分类审核; 在“云端” 平台上对公民代理人的资质进行智能认证，对案件的 性质、类别和难易程度进行“智慧”评估, 将服务申请 人、案件和志愿者进行精准匹配。在线下, 组建公民 代理志愿服务组织的群落, 组织经过认证的志愿者开 展公民代理服务, 对公民代理志愿服务组织进行培训、 运营和考评, 依托网络组织内部的“云平台”建立公民 代理志愿服务的大数据并进行服务活动的质量监控。 通过 “线上——线下”的密切互动, 打通政府机构与相 关部门的行政壁垒和“信息孤岛”，从而达到消解审查 和监管公民代理人资质和行为的盲区，加速公民代理 事务的服务处置流程, 提升公民代理诉讼案件质量的 目的。

\section{致谢}

2019 年上海市哲学社会科学规划一般课题“大学 生文化自信培育的“媒介融合”机制研究” (2019BKS010)；2019 年度中国——上海合作组织 
国际司法交流合作培训基地研究项目“全球化视域下 中华文化在 “一带一路, 传播的路径探究” (19SHJD039); 2019 年上海政法学院科研项目“中华 传统文化的创造性转化与创新性发展探究” (2019XJ10)。

\section{REFERENCES}

[1] Dongdong Huang, Public legal service and information technology: Foreign experience and China's problems--taking Legal Aid for Example, E-Government, vol.169, no.1, 2017, pp.95-101. DOI:10.16582/j.cnki.dzzw.2017.01.012

[2] Hao Yu, The opportunity, challenges and solutions of the management of government data in the Age of Big Data, Chinese Public Administration,vol.357, no.3, 2015, pp.127-130. DOI: 10. 3782 / j.issn.1006-0863.2015.03.24

[3] Baojian Zhang, Guoqiang Sun, Xiaoyue Ren, Literature Review of Network Organization Governance Model, Commercial Research, vol.455, no.3, 2015, pp.36-45 DOI: 10.13902/j.cnki.syyj. 2015.03.005

[4] Liping Lin, New Organization Paradigm: A Review of Network Organization Theory, Economic and Social Development,vol.4, no.11, 2006, pp.28-31.DOI :10.16523/j.45-1319.2006.11.009

[5] Xianming Wang, Ye Li, Collaborative Innovation as a Strategic Choice

for Universities: from the Perspective of Economics, Journal of National Academy of Education Administration,vol.24, no.2, 2014, pp.24-29.DOI :DOI:10.3969/j.issn.1672-4038.2014 .02 .005

[6] Tan Chan,The Turn of Innovation from Big Data Driven Social Governance, Administrative Tribun,vol.23, no.6, 2016, pp.1-5. DOI:10.3969/j.issn.1005-460X.2016.06.002 